\title{
Efeito do Cobre na Atividade da Enzima Pirogalol Peroxidase em Plantas De Myriophyllum aquaticum Cultivadas em SoluÇão NUTRITIVA ${ }^{1}$
}

\author{
Effect of Copper on the Activity of Pirogalol Peroxidase in Myriophyllum aquaticum Plants \\ Cultivated in Nutritives Solution
}

\author{
DOMINGOS, V.D. ${ }^{2}$, BOARO, C.S.F. ${ }^{3}$, CATANEO, A.C. ${ }^{4} ;$ LOBO, T.F. ${ }^{5}$ e MARTINS, D. ${ }^{6}$
}

\begin{abstract}
RESUMO - Myriophyllum aquaticum é uma planta perene, herbácea, que pode se desenvolver totalmente submersa ou com a porção terminal dos ramos acima da superficie da água. É também considerada uma planta daninha que possui elevado potencial de colonização, o qual, dependendo da densidade populacional, pode causar aumento no teor de matéria orgânica e redução de oxigênio na água, comprometendo a qualidade da água e seus usos múltiplos. O objetivo do presente trabalho foi verificar a influência do cobre na atividade da pirogalol peroxidase de plantas de $M$. aquaticum submetidas à solução nutritiva contendo concentrações de cobre de 1,$2 ; 11,2 ; 21,2 ; 31,2 ;$ e $41,2 \mu \mathrm{g} \mathrm{L} \mathrm{L}^{-1}$. O experimento foi conduzido em um delineamento experimental inteiramente casualizado, com quatro repetições e cinco tratamentos, aos quais as plantas foram submetidas durante 21 dias. Aos 81 dias após a instalação das mudas em solução nutritiva contendo os diferentes niveis de cobre, as folhas foram colhidas a partir do ápice da planta até o final do ramo, que não estavam em contato com a solução. Esse material fresco foi envolvido por plástico transparente e papel-alumínio e, a seguir, congelado em nitrogênio liquido, sendo armazenado em freezer a $-20{ }^{\circ} \mathrm{C}$ até o momento da determinação da atividade da enzima pirogalol peroxidase. A atividade da enzima foi progressiva com o aumento das doses de cobre. As plantas cultivadas com $40 \mu \mathrm{g} \mathrm{L}^{-1}$ de $\mathrm{Cu}^{2+}$ após três semanas, com base em avaliação visual, apresentaram redução no desenvolvimento.
\end{abstract}

Palavras-chave: estresse oxidativo, tolerância, planta daninha e planta aquática.

\begin{abstract}
Myriophyllum aquaticum is a perennial, herbaceous plant which grows totally submerged or with the terminal portion of the branches above the surface of the water. It is also considered to be a harmful plant, possessing a high colonization potential which, depending on population density, can increase the organic matter content and reduce oxygen in the water, compromising the quality of water and its multiple uses. The objective of the present work was to verify the effect of copper on the activity of pirogalol peroxidase in $\boldsymbol{M}$. aquaticum plants submitted to nutritive solution containing copper concentrations of $1.2 ; 11.2 ; 21.2 ; 31.2$ and $41.2 \mu g L^{-1}$. The experiment was carried out in a randomized complete design with 4 replicates and 5 treatments for 21 days Eighty-one days later, the leaves were collected starting from the apex of the plant to the end of the branch, which was not in contact with the solution. This fresh material was involved by transparent plastic and aluminum foil, frozen in liquid nitrogen, stored in freezer to $-20{ }^{\circ} \mathrm{C}$ until determination of the enzyme activity. Enzyme activity increased with the increase of the copper doses. The plants cultivated with $40 \mu \mathrm{g} \mathrm{L}^{-1}$ of $\mathrm{Cu}^{2+}$ showed a reduced development, after three weeks, based on visual examination.
\end{abstract}

Key words: oxidative stress, tolerance, weed and aquatic plant.

Recebido para publicação em 15.12.2004 e na forma revisada em 1.3.2005.

Eng.-Agr ${ }^{\text {. }}$, M.S., FCA/UNESP, Caixa Postal 237, 18603-970 Botucatu-SP, <vanessadavid@fca.unesp.br>; ${ }^{3}$ Professora Livre Docente, Departamento de Botânica, UNESP; ${ }^{4}$ Professora, Dra., Departamento de Bioquímica, UNESP; ${ }^{5}$ Mestrando, FCA/UNESP; ${ }^{6}$ Professor Livre Docente, Departamento de Agricultura, FCA/UNESP. 


\section{INTRODUÇÃO}

No processo de suas atividades vitais, as plantas aquáticas, como Myriophyllum aquaticum, absorvem substâncias dissolvidas de natureza química diferente, incluindo metais pesados, que podem estar presentes em corpos hídricos resultantes de atividades industriais ou agrícolas. As plantas aquáticas, independentemente dos grupos ecológicos aos quais pertencem, colonizam ambientes que apresentam poluição média de metais pesados e podem acumular elementos em concentrações altas, porém o acúmulo de tais metais ocorre até determinados limites, resultando em diferentes efeitos na planta; dependendo da espécie, ela se adapta às altas doses de metais ou morre. Das muitas espécies avaliadas em corpos hídricos na Rússia, uma espécie do gênero Myriophyllum (Myriophyllum spicatum), durante o seu crescimento, acumulou metais pesados, a exemplo do cobre, em concentrações maiores do que na água (Mikryakova, 2002).

O crescimento excessivo de plantas aquáticas tem causado sérios problemas, como os prejuízos financeiros causados às empresas hidrelétricas, bem como à qualidade da água destinada aos usos múltiplos pela sociedade. Em conseqüência, quanto maior a disponibilidade de nutrientes, maior a quantidade de biomassa produzida pelas plantas aquáticas, o que pode ocasionar maior consumo de oxigênio, pelo aumento no teor de matéria orgânica devido à decomposição de sua biomassa (Larcher, 1986).

M. aquaticum, conhecida como pinheirinho-d'água, é uma planta daninha com elevado potencial de colonização que, dependendo da densidade populacional, pode causar aumento no teor de matéria orgânica e redução de oxigênio na água, comprometendo a qualidade desta e seus usos múltiplos, sendo geralmente encontrada em ecossistemas altamente alterados pelo homem (Guillarmod, 1977).

A espécie, caracterizada como perene e herbácea, pode se desenvolver totalmente submersa ou com a porção terminal dos ramos emersa, que constituem propágulos vegetativos utilizados como o principal modo de reprodução. O enraizamento mantém-se no fundo de lagos com até $2 \mathrm{~m}$ de profundidade, ou nas margens, deixando que os ramos avancem pela água (Kissmann, 1997). O ambiente propício ao seu desenvolvimento é o de água doce, parada ou com fraca movimentação, com elevado teor de nutrientes, especialmente nitrogênio, e temperatura entre 8 e $30^{\circ} \mathrm{C}$. Dentre as suas estratégias adaptativas encontra-se a sua tolerância à salinidade, com inibição de seu desenvolvimento na presença de concentrações de cloreto de sódio na água acima de 1\% (Kissmann, 1997).

Das diversas formas de contaminação de ambientes aquáticos decorrentes de resíduos industriais e agrícolas, os metais pesados são considerados os principais poluentes e potencialmente citotóxicos, carcinogênicos e mutagênicos, embora alguns sejam essenciais em processos metabólicos vitais aos organismos, a exemplo do cobre (Hadjiliadis, 1997).

O cobre, micronutriente essencial, é componente de várias enzimas, principalmente as que atuam no fluxo de elétrons, catalisando reações redox. Entretanto, quando em excesso, esse elemento pode interferir em vários processos fisiológicos, provocando injúrias nas membranas celulares, pela ligação em grupos sulfidril das proteínas de membrana e pela indução de peroxidação de lipídio. A toxidez de cobre também pode causar estresse oxidativo, por meio da geração de espécies reativas de oxigênio, como $\mathrm{O}_{2}^{-}, \mathrm{H}_{2} \mathrm{O}_{2}$ e HO. Em condições de toxidez, podem ser ativados alguns mecanismos protetores, como o aumento da atividade de enzimas antioxidantes, entre as quais peroxidase, catalase e superóxido dismutase, que podem aumentar a tolerância da planta ao estresse (Salisbury \& Ross, 1992).

O mecanismo de interação de substâncias - como os aminoácidos - com íons não é muito conhecido, porém sabe-se que essas substâncias reagem quando expostas a íons metais para formar complexos que conferem às plantas aquáticas a alta capacidade de absorção de íons metálicos (Nigam et al., 1998).

A remoção de metais pesados dos ambientes tem originado vários estudos, principalmente com plantas aquáticas, as quais se destacam como biofiltros, conseqüência da biossorção de elementos químicos, ou funcionando como indicadores de poluição, que confere seu potencial em relação ao acúmulo 
de metais (Schneider et al., 1999; Heisey \& Damman, 1982; Cymerman-Samecka \& Kempers, 1996). A biossorção pode ser classificada como acumulação/precipitação extracelular, sorção/precipitação na superficie da célula e acumulação intracelular, podendo ocorrer por complexação, coordenação, quelação de metais, troca de íons, adsorção e microprecipitação (Beolchini, 1997).

A concentração de cobre em corpos hídricos pode variar de 2 a $31 \mu \mathrm{g} \mathrm{L}^{-1}$ na água e 3,3 a 9,6 $\mathrm{mg} \mathrm{kg}^{-1}$ de massa seca em Myriophyllum verticilatum, de acordo com amostragem realizada no rio Wroclaw, na Polônia, dependendo da proximidade do efluente (CymermanSamecka \& Kempers, 1996). Em outros estudos, para a concentração de cobre na água de vários rios na Alemanha foram detectados valores entre 3 e $198 \mu \mathrm{g} \mathrm{L} \mathrm{L}^{-1}$, os quais estão acima do limite permitido $\left(3 \mu \mathrm{g} \mathrm{L}^{-1}\right)$ pelos órgãos institucionais de qualidade da água (Cymerman-Samecka \& Kempers, 2001). A capacidade de adsorção de metais pesados foi determinada em $M$. spicatum, que apresentou 10,37 $\mathrm{mg} \mathrm{g}^{-1}$ para cobre (Keskinkan, 2003).

No Brasil, foram realizados estudos no reservatório de Jupiá, localizado no rio Tietê, referentes à concentração de metais na biomassa de Egeria densa, Egeria najas e Ceratophyllum demersum, as quais apresentaram teores médios de 20,7, 18,0 e 24,2 $\mathrm{mg} \mathrm{kg}^{-1}$ de cobre no verão e 5,9, 5,7 e 4,6 $\mathrm{mg} \mathrm{kg}^{-1}$ no inverno, respectivamente, correspondente a uma variação sazonal de $80 \%$ para as três espécies (Correa et al., 2003)

O presente trabalho de pesquisa objetivou verificar a influência do cobre na atividade da pirogalol peroxidase de plantas de $M$. aquaticum submetidas a diferentes concentrações de cobre na solução de Sarruge et al. (1975), com o intuito de auxiliar no conhecimento da biologia da espécie em ambientes poluídos por metais pesados, como subsídio ao estabelecimento de programas de controle.

\section{MATERIAL E MÉTODOS}

O experimento foi instalado em casa de vegetação pertencente ao Núcleo de Pesquisas Avançadas em Matologia (NUPAM) da FCA/ UNESP, localizado na Fazenda Experimental Lageado, no campus de Botucatu-SP.
As mudas foram obtidas em área de várzea da Fazenda Edgardia, também pertencente à UNESP, campus de Botucatu, padronizadas com $20 \mathrm{~cm}$ de comprimento. A seguir foram transferidas para vasos plásticos com $13,8 \mathrm{~cm}$ de largura x $11,8 \mathrm{~cm}$ de altura x $28,3 \mathrm{~cm}$ comprimento, contendo um litro de solução nutritiva de Sarruge et al. (1975) diluída a 60\% e arejada por um sistema constituido de compressores de ar e mangueiras de plástico. Foram realizadas as trocas das soluções em intervalos de três dias, mantendo o $\mathrm{pH}$ entre 5,0 e 5,5, utilizando-se $\mathrm{HCl} 0,5 \mathrm{~mol} \mathrm{~L}^{-1}$ ou $\mathrm{NaOH}$ $0,5 \mathrm{~mol} \mathrm{~L}^{-1}$. A manutenção das plantas em solução nutritiva diluída a $60 \%$ durante 42 dias propiciou condições favoráveis à recuperação das mudas, as quais, no momento da coleta, apresentavam manchas cloróticas, de cor marrom, em todas as folhas. Após esse período, procedeu-se à variação das doses de cobre na solução nutritiva diluída a $60 \%$, momento em que as plantas bem desenvolvidas preenchiam toda a extensão da área do vaso.

O delineamento experimental utilizado foi o inteiramente casualizado, com quatro repetições e cinco doses de cobre $(1,2 ; 11,2$; 21,2 ; 31,2 ; e $\left.41,2 \mu \mathrm{g} \mathrm{L}^{-1}\right)$. As plantas submetidas ao tratamento testemunha continham $1,2 \mu \mathrm{g} \mathrm{Cu} \mathrm{L} \mathrm{L}^{-1}$ - nivel do elemento preconizado para a solução nutritiva diluída a $60 \%$. As doses de cobre foram determinadas com base na concentração máxima permitida na água, que não pode ser maior que $20 \mu \mathrm{g} \mathrm{L}^{-1}$, de acordo com a CONAMA. A composição química da solução de Sarruge (1975), diluída a 60\%, constituiu-se de $\mathrm{N}, \mathrm{P}, \mathrm{K}, \mathrm{Ca}, \mathrm{Mg}$ e $\mathrm{S}$, nas concentrações de $126 ; 18,6 ; 140,4 ; 120 ; 28,8$; e 38,4 $\mathrm{mg} \mathrm{L}^{-1}$ e de Fe, B, Mn, $\mathrm{Zn}, \mathrm{Cu}^{2+}$ e Mo nas concentrações de 3,$0 ; 0,3 ; 0,3 ; 0,03 ; 0,0012$; e $0,0006 \mathrm{mg} \mathrm{L}^{-1}$, respectivamente.

No preparo da solução-estoque de micronutrientes foram utilizados $2,86 \mathrm{~g}$ de $\mathrm{H}_{3} \mathrm{BO}_{3}$, $1,81 \mathrm{~g}$ de $\mathrm{MnCl}_{2}$. $4 \mathrm{H}_{2} \mathrm{O}, 0,10 \mathrm{~g}$ de $\mathrm{ZnCl}_{2}, 0,04 \mathrm{~g}$ de $\mathrm{CuCl}_{2}$ e $0,02 \mathrm{~g}$ de $\mathrm{H}_{2} \mathrm{MoO}_{4} \cdot \mathrm{H}_{2} \mathrm{O}$, sendo diluídos em água destilada, em um volume final de $1 \mathrm{~L}$.

A solução de Fe-EDTA foi preparada por meio da diluição separada de 26,2 g de EDTA dissódico (etileno diamino tetra acetato de sódico) e de $24 \mathrm{~g}$ de $\mathrm{FeSO}_{4} \cdot 7 \mathrm{H}_{2} \mathrm{O}$ em água destilada, misturados a seguir. Essa solução, após ter sido arejada por meio de um

Planta Daninha, Viçosa-MG, v. 23, n. 2, p. 375-380, 2005 
compressor durante 12 horas, foi filtrada em papel e teve seu volume completo para $1 \mathrm{~L}$. A solução foi armazenada em frasco escuro de vidro e acondicionada em freezer até a sua utilização.

Aos 81 dias após a instalação das mudas em solução nutritiva contendo os diferentes niveis de cobre, as folhas colhidas a partir do ápice da planta até o final do ramo, que não estavam em contato com a solução, foram pesadas para obter massa fresca em quantidade superior a $1 \mathrm{~g}$. Esse material fresco foi envolvido por plástico transparente e papelalumínio e, a seguir, congelado em nitrogênio líquido, sendo armazenado em freezer a $-20^{\circ} \mathrm{C}$ até o momento da determinação da atividade da enzima pirogalol peroxidase.

Para isso, o preparo do extrato enzimático foi realizado de acordo com metodologia descrita por Ekler et al. (1993). Assim, o material vegetal foi homogeneizado com $5 \mathrm{~mL}$ de tampão Tris- $\mathrm{HCl} 0,2 \mathrm{~mol} \mathrm{~L}^{-1}$ a $\mathrm{pH} 7,8$ contendo $1 \mathrm{mmol} \mathrm{L}^{-1}$ de EDTA e 7,5\% (peso/volume) de polivinilpolipirrolidona (PVPP), em almofariz gelado e com areia previamente lavada e esterilizada. Em seguida, o homogeneizado foi filtrado em malha de organza, utilizando-se béquer previamente resfriado e centrifugado a $14.000 \mathrm{rpm}$ durante $20 \mathrm{~min}$ a $4{ }^{\circ} \mathrm{C}$, posteriormente, o sobrenadante foi transferido para frascos "eppendorf", que foram armazenados em freezer a $-20{ }^{\circ} \mathrm{C}$.

O sistema de reação para determinação da atividade da pirogalol peroxidase (Knorzer et al. 1996) constituiu-se de $500 \mu \mathrm{L}$ de tampão fosfato de potássio (100 $\left.\mathrm{mmol} \mathrm{L}^{-1} \mathrm{pH} 6,5\right), 30 \mu \mathrm{L}$ de extrato enzimático, $250 \mu \mathrm{L}$ de Pirogalol e $220 \mu \mathrm{L}$ de $\mathrm{H}_{2} \mathrm{O}_{2} \mathrm{O}$ branco continha o mesmo sistema de reaçã̃o, com exceção do extrato enzimático. O sistema de reação foi mantido à temperatura ambiente por cinco minutos, sendo a seguir lidos os valores de absorbância em espectrofotômetro em comprimento de onda igual a $430 \mathrm{~nm}$. A formação de purpurogalina foi determinada utilizando-se o coeficiente de extinção molar de $2,47 \mathrm{mmol} \mathrm{cm}^{-1}$.

A atividade da enzima expressa em $\mu \mathrm{mol}$ de purpurogalina é o produto resultante da reação da pirogalol peroxidase na eliminação das espécies reativas de oxigênio, responsáveis pelo estresse oxidativo.
Os teores de proteínas solúveis nos extratos enzimáticos foram determinados pelo método de Lowry et al. (1951), utilizando reativo de Folin. As leituras de absorbância foram feitas em espectrofotômetro em comprimento de onda igual a $660 \mathrm{~nm}$. A concentração de proteína da amostra foi determinada utilizando-se curva-padrão composta de albumina sérica bovina (BSA).

Os resultados obtidos foram submetidos à análise de regressão, realizada com a média, usando o programa Jandel Sigma Stat 2.0.

\section{RESULTADOS E DISCUSSÃO}

A atividade da pirogalol peroxidase encontra-se na Figura 1 e Tabela 1. Aos 81 dias após o transplantio, correspondente à terceira semana de exposição às doses de cobre, constataram-se aumentos crescentes da atividade enzimática com o aumento das concentrações. Observou-se na análise de regressão que o melhor ajuste para esse comportamento foi o linear, que apresentou coeficiente de determinação de 0,83 ( $\mathrm{p}<0,05)$. O mecanismo de tolerância aos metais não envolve apenas a atividade de enzimas, mas também pode ser relacionado à complexação do cobre com outras substâncias. $\mathrm{O}$ acúmulo de metais pesados em várias partes de plantas superiores está sempre associado a diversas alterações celulares, que contribuem às vezes para capacidade de tolerância das plantas ao metal, como a ligação de quantidades consideráveis de cobre com substâncias pécticas nas paredes de células do córtex da raiz (Mengel \& Kirkby, 1987).

Devi \& Prasad (1998) estudaram a toxicidade de cobre na planta aquática submersa

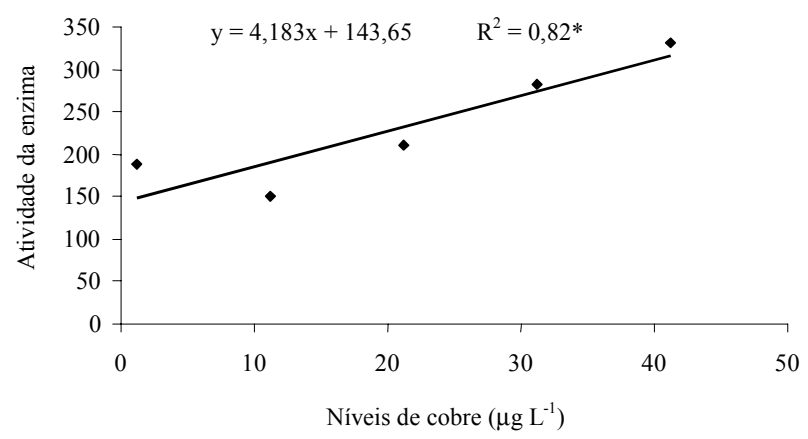

Figura 1 - Atividade da pirogalol peroxidase. 
Tabela 1 - Atividade da pirogalol peroxidase após três semanas de exposição ao cobre

\begin{tabular}{|c|c|}
\hline $\begin{array}{l}\text { Dose de cobre } \\
\qquad\left(\mu \mathrm{g} \mathrm{L}^{-1}\right)\end{array}$ & $\begin{array}{c}\text { Atividade da enzima } \\
\left(\text { nmol } \text { min }^{-1} \mathrm{mg} \text { proteína }\right. \\
\end{array}$ \\
\hline 1,2 & 187,7 \\
\hline 11,2 & 149,7 \\
\hline 21,2 & 211,3 \\
\hline 31,2 & 282,7 \\
\hline 41,2 & 330,3 \\
\hline
\end{tabular}

C. demersum e a resposta da enzima antioxidante ascorbato peroxidase (APX). As plantas foram submetidas a 2 e $4 \mu \mathrm{M}$ de $\mathrm{Cu}$, correspondentes a 127,1 e $254,2 \mu \mathrm{g} \mathrm{L}^{-1}$, respectivamente, da solução de Hoagland diluída a 1/ 10 de sua concentração durante 24 horas em ambiente fora de casa de vegetação. Os pesquisadores verificaram que o acúmulo de cobre aumentou o estresse oxidativo, resultando em injúria da membrana celular correlacionada com a peroxidação de lipídio.

As plantas utilizam mecanismos de proteção para eliminar radicais livres e peróxidos - como o aumento da atividade de uma ou mais enzimas antioxidantes - bem como substâncias antioxidantes, como a glutationa. Entretanto, diferentes respostas dessas enzimas ao estresse causado pelo metal podem ser verificadas, relacionadas à variabilidade genética entre as espécies, o que determina a variação da produção de radicais livres. A atividade da APX aumentou 39 e $41 \%$ a 2 e $4 \mu \mathrm{mol} \mathrm{L}^{-1}$, respectivamente, sendo a maior atividade observada na catalase $(109 \%)$ a $2 \mu \mathrm{mol} \mathrm{L} \mathrm{L}^{-1}$. Portanto, o aumento da atividade dessas enzimas, induzida pelo cobre indica que houve aumento na oxidação de $\mathrm{H}_{2} \mathrm{O}_{2}$, reduzindo assim o estresse oxidativo causado pelo metal. Contudo, a atividade dessas enzimas foi menor quando as plantas foram tratadas com $4 \mu \mathrm{mol} \mathrm{L}{ }^{-1}$ de cobre, considerada dose letal para C. demersum; isso pode indicar que em altas concentrações de cobre essas enzimas podem não ser suficientes para proteger as plantas das injúrias causadas pelo estresse oxidativo (Devi \& Prasad, 1998).

O mecanismo de proteção ao estresse oxidativo consiste também na ação de outras moléculas, como a glutationa e outros thiols não-protéicos. Esses compostos e enzimas podem não ser suficientes para a redução do estresse, dependendo dos efeitos tóxicos causados pelas concentrações elevadas do metal (Devi \& Prasad, 1998).

Quanto à atividade da pirogalol peroxidase em $M$. aquaticum, foi observado aumento de $45,3 \%$ entre 10 e $40 \mu \mathrm{g} \mathrm{L}^{-1} \mathrm{com}$ o incremento das concentrações de cobre na terceira semana. Entretanto, não foi possivel identificar a dose letal para a espécie em estudo, como encontrado nos resultados de Devi \& Prasad (1998), que utilizaram doses seis vezes maiores.

Em outras espécies deste gênero, como M. spicatum, foi constatada tolerância a elevadas concentrações de cobre na água (40-48 $\mu \mathrm{g} \mathrm{L}^{-1}$ ), resultando em acúmulos na planta de $720-1.040 \mathrm{mg} \mathrm{kg}^{-1}$, que corresponde a concentrações acima do nivel de toxidez para a maioria das plantas. Esta espécie coloniza facilmente águas poluídas com metais pesados, devido ao seu potencial de adaptação a ambientes alterados (Cymerman-Samecka \& Kempers, 2003). Esses valores são considerados altos para plantas aquáticas, comparados aos de outras espécies, como Brachiaria arrecta, Eichhornia crassipes, Pistia stratiotes e Salvinia molesta, que apresentaram teores de cobre correspondentes a 5,63; 9,75; 8,58, e $11,14 \mathrm{mg} \mathrm{kg}^{-1}$, respectivamente (Martins et al., 2003).

As plantas cultivadas com $40 \mu \mathrm{g} \mathrm{L}^{-1}$ de $\mathrm{Cu}$ após três semanas, com base em avaliação visual, apresentaram redução no desenvolvimento. Isso, provavelmente, pode estar relacionado à formação de complexos de cobre e nitrogênio, bem como a compostos aminados pela afinidade entre ambos, o que indisponiliza o nutriente para as funções metabólicas (Mengel \& Kerkby, 1987). No entanto, outros estudos poderiam ser realizados para avaliar essa hipótese, com o intuito de identificar o conteúdo de aminoácidos e compostos aminados na planta, assim como outros mecanismos de proteção ao estresse oxidativo.

Dessa forma, M. aquaticum apresentou tolerância ao estresse oxidativo causado pelo cobre com base no aumento da atividade da pirogalol peroxidase, que foi crescente com as doses de cobre. Esse fato pode explicar a ocorrência desta espécie em ambiente poluído com metais pesados. A atividade da enzima

Planta Daninha, Viçosa-MG, v. 23, n. 2, p. 375-380, 2005 
foi progressiva com o aumento das doses de cobre.

\section{LITERATURA CITADA}

BEOLCHINI, V. F. Removal of heavy metal ions by biosorption: a review. Hydrometallurgy, v. 44, p. 301-316, 1997.

CYMERMAN-SAMECKA, A.; KEMPERS, A.J. Bioaccumulation of heavy metals by aquatic macrophytes around wroclaw, Poland. Ecotoxicol. Environ. Safety, v. 35, p. 242-247, 1996.

CYMERMAN-SAMECKA, A.; KEMPERS, A. J. Toxic metals in aquatic plants surviving in surface water polluted by copper mining industry. Ecotoxicol. Environ. Safety, v. 59, p. 64-69, 2003.

CYMERMAN-SAMECKA, A.; KEMPERS, A. J. Concentrations of heavy metals and plant nutrient in water, sediments and aquatic macrophytes of anthropogenic lakes (former open brown coal mines) differing in stage of acidification. Total Environ., v. 281, p. 87-98, 2001.

CORREA, M. R.; VELINI, E. D.; ARRUDA, D. P. Composição química e bromatológica de Egeria densa, Egeria najas e Ceratophyllum demersum. Planta Daninha, v. 21, p. $7-13,2003$.

DEVI, S. R.; PRASAD, M. N. V. Copper toxicity in Ceratophyllum demersum L. (Coontail), a free floating macrophyte: Response of antioxidant enzymes and antioxidants. Plant Sci., v. 138, p. 157-165, 1998.

EKLER, Z.; DUTKA, F.; STEPHENSON, G.R. Safener effects on acetochlor toxicity, uptake, metabolism and glutathione S-transferase activity in maize. Weed Res., v. 33, p. 311-318, 1993.

GUILLARMOND, A. J. Myriophyllum, an increasing water weed menace for South Africa. South Afr. J. Sci., v. 73, n. 3, p. 89-90, 1977.

HADJILIADIS, N. D. Cytotoxicity, mutagenic and carcinogenic potential of heavy metals related to human environment. Dordrecht: Kluwer, 1997. 629 p. (NATOASI Séries, 2; Environment, v. 26).
HEISEY, R. M.; DAMMAN, A. W. H. Cooper and lead uptake by aquatic macrophytes in eastern Connecticut, U.S.A. Aquatic Bot., v. 14, p. 213-229, 1982.

KESKINKAN, O. et al. Heavy metal adsorption characteristics of a submerged aquatic plant (Myriophyllum spicatum). Process Biochem., v. 39, p. 179-183, 2003.

KISSMANN, K. G. Plantas infestantes e nocivas. 2.ed. São Paulo: Basf Brasileira, 1997. 825 p.

KNÖRZER, O. C.; DURNER, J.; BÖGER, P. Alterations in the antioxidative system of suspension-cultured soybean cells (Glycine max) induced by oxidative stress. Physiol. Plant. , v. 97, p. 388-396, 1996.

LARCHER, W. Ecofisiologia vegetal. São Paulo: Pedagógica e Universitária, 1986. 319 p.

MARTINS, D. et al. Caracterização química das plantas aquáticas coletadas no reservatório de Salto Grande (Americana-SP). Planta Daninha, v. 21, p. 21-25, 2003.

MIKRYAKOVA, T. F. Accumulation of heavy metals by macrophytes at different levels of pollution of aquatic medium. Water Res., v. 29, n. 2, p. 230-32, 2002.

MENGEL, K.; KIRKBY, E. A. Principles of plant nutrition. 4.ed. Bern: International Potash Institute Bern, 1987. $677 \mathrm{p}$.

NIGAM, K. D. P. et al. A mathematical model for metal ions uptake by aquatic plants for waste water treatment. Environ. Model. Assessment, v. 3, 249-258, 1998.

SALISBURY, F. B.; ROSS, C. W. Plant physiology. 4.ed. Califórnia: Wadsworth Publishing Company, 1992. $682 \mathrm{p}$.

SARRUGE, J. R. et. al. Soluções nutritivas. Summa Phytopathol., v. 1, n. 3, p. 231-233, 1975.

SCHNEIDER, I. A. H. ; SMITH, R. W.; RUBIO, J. Effect mining chemicals on biosorption of $\mathrm{Cu}$ (II) by the non-living biomass of the macrophyte Potamogeton lucens. Miner. Eng., v. 12, n. 3, p. 255-260, 1999. 